\title{
The Symbolic Relevance of Feedback: Return and Disclosure of Genomic Research Results of Breast Cancer Patients in Belgium, Germany and the UK Imme Petersen* and Regine Kollek
}

Research Centre for Biotechnology, Society and the Environment, University of Hamburg, Hamburg, Germany

\begin{abstract}
Objective: Current bioethical debates on privacy in genomic research have not yet sufficiently considered the ethical duty to return individual study results. Anonymizing data, albeit problematic in genomics, would alleviate some privacy concerns but hampers access to individual research results. However, little empirical data exist on the concerns about losing privacy and the expectations of receiving study results on the part of the patients who participate in genomic research. This paper's objective is to elucidate how participants conceptualize the tension between data privacy and access in genomic research.
\end{abstract}

Methods: As comparative studies are missing, we explored participant attitudes and perceptions about privacy concerns and expectations of receiving study results in three national study populations (Belgium, $n=152$; United Kingdom, $n=122$; and Germany, $n=122$ ). The recruited survey participants were breast cancer patients who provided bio-specimens to genomic cancer research.

Results: Only half the respondents believed that legislation in their country is sufficient to protect health information. However, potentially stigmatizing health conditions and genetic test results were scored as sensitive data. Regarding third-party disclosure, $48 \%$ did not want their health data disclosed to family members without consent; more than $80 \%$ wanted to be protected against unauthorized data transfer to insurance companies and employers. The respondents preferred receiving aggregate rather than individual study results. The preferred contact methods were a circular letter by mail (aggregate results) and a consultation with the physician (individual results). Regarding national differences, the survey results were quite homogeneous; only the British survey showed a few statistically variations.

Conclusion: Participants in genomic research regarded the tissue they provided as something personal and private. Hence, they expected some form of reciprocity expressing appreciation towards the study participant. Our survey suggests that participant expectations about what they should receive can be primarily of symbolical relevance, e.g: a summary of aggregate study findings.

Keywords: Disclosure; Confidentiality; Data protection; Feedback; Breast cancer; Genomic research; International study

\section{Introduction}

Confidentiality of health information has become a dominant topic in the bioethical debate, in the context of both research and clinical care. It is widely recognized that health-related data have to be protected from third-party disclosure and deployment, which is deemed to be an intrusion into the providers' personal sphere [1]. By third-party disclosure, we mean the communication of (health) information to someone else other than the person from whom the data stem. In this paper, we explore three different forms of third-party disclosure. First, the disclosure is authorized by the patient's consent; second, the disclosure is not authorized by the patient's consent; third, the disclosure is not authorized but implicitly accepted by the patient. Particularly in the context of genomic research, there is much concern about losing privacy through unauthorized disclosure and genetic discrimination [2-5]. Experts in biobank governance, for instance, consistently frame people's concerns about the collection, distribution and utilization of their biological, medical and lifestyle data as privacy concerns [6-8].

In the European Union, recent legislation activities have met these fears with ongoing work to enact a new General Data Protection Regulation. Compared with the current EU Directive on Data Protection, which has been described as the most far reaching Data Protection regime in the world [9], the new regulation may implement an even stricter regime [10]. The guiding principle for identifiable data is to restrict the possibility to process such data without re-consent, the possibility to re-use them for purposes other than what they were collected for, and the possibility to store data for longer periods of time.
Health-related data in research should as a general rule be anonymized or, if anonymization is not possible, pseudonymized under the highest technical security standards.

Despite legislative activity and ethical debate, few empirical studies have investigated perceptions and attitudes of patients on confidentiality and disclosure of health information, especially genomic information, in Europe. An Eurobarometer survey from 2010 shows that health data are framed as personal data by 3 out of 4 survey respondents (74\%), and the majority of them stated that they refuse to disclose personal health information, e.g: on the Internet [11]. However, regarding medical data as personal does not prevent individuals from research participation. Another Eurobarometer survey from 2010 reveals that almost half of the respondents (46\%) are willing to provide information about themselves to a biobank [12]. According to this survey, certain types of information invoke more anxiety than other types. People

*Corresponding author: Imme Petersen, PhD, Research Centre for Biotechnology, Society and the Environment, University of Hamburg, Lottestrasse 55, 22529 Hamburg, Germany, Tel: (+49) 407410 56312, Fax: (+49) 407410 56315, E-mail: imme.petersen@uni-hamburg.de

Received May 28, 2015; Accepted July 07, 2015; Published July 31, 2015

Citation: Petersen I, Kollek R (2015) The Symbolic Relevance of Feedback: Return and Disclosure of Genomic Research Results of Breast Cancer Patients in Belgium, Germany and the UK. J Clin Res Bioeth 6: 230. doi:10.4172/21559627.1000230

Copyright: ( $) 2015$ Petersen I, et al. This is an open-access article distributed under the terms of the Creative Commons Attribution License, which permits unrestricted use, distribution, and reproduction in any medium, provided the original author and source are credited. 
seem less concerned about giving information about their lifestyle, such as diet, exercise habits, etc. (24\%), but are more concerned about giving samples of blood and tissue (both $30 \%)$, medical records $(33 \%)$ or genetic profiles (34\%). Generally, the respondents' willingness to participate in research is negatively correlated with concerns about privacy $[12,13]$. This implies that inhabitants of European countries that score high on a privacy concern scale are reluctant to provide biospecimens and health-related data to research. With regard to the three countries involved in our study, the reluctance was above-average in Germany in the Eurobarometer survey, in particular regarding genetic profiles (48\%) and medical records (46\%), whereas in Belgium and the UK the attitudes corresponded to the European average.

There is some empirical evidence that issues of privacy and data protection are indeed important for participants in the context of genomic research [14-18]. It is widely recognized that people worry about data abuse by insurance companies and employers, and many ethicists therefore have called for reliable and sustainable data protection $[2,13,19,20]$. However, two recent focus group studies revealed that people are quite aware of the fact that data can never be fully protected in an information society and that their personal data is already 'out there' $[16,21]$. Such an attitude implies that the meaning and value of confidentiality is dependent on the context in which it is applied and used [22].

In many contexts, anonymizing samples would serve to alleviate privacy concerns. It is however dysfunctional in the context of genetic or genomic research as individuals can at least in principle be identified even if samples are anonymized if a reference sample is available, e.g: by using public databases such as from the Genome-Wide Association Study $[23,24]$. Furthermore, genomic researchers aspire after identifiable data collections to correlate biological and medical data with information about lifestyle from individuals in longitudinal studies. Anonymizing samples also makes it impossible for researchers to return individual research results [25]. In ethical terms, this may be even more important than possible privacy breaches by intentionally or accidentally de-anonymized samples.

Support for the ethical duty to return research results referring to individual research subjects is currently growing even if the debate as to whether to return research results to study participants at all is controversial [26] and non-disclosure is still prevalent in current genomic practice [27]. This demand is usually based on the ethical principles of individual autonomy, respect for the patient, beneficence, and the acknowledgement that translational genomic research cannot progress without the engagement of research participants and patient communities [28]. Hence, commentators have called upon researchers to routinely return individual research results. Some authors restrict this obligation to the communication of general results referring to the sample of participants [29-31], while others argue for the routine disclosure of research results referring to an individual [32-37]. Fully disclosing of individual results, including all raw sequencing data, is disclaimed by many researchers. They want to limit the recognized duty of returning study results to warning someone only if and when his or her life is threatened and serious harm can be avoided [38].

However, results from genomic research may help study participants to take control of their life, realize or adjust life plans, or revise their strategies for coping [39]. The few existing empirical studies show that participants and the general public have a particular interest in receiving such results, and it has been acknowledged that disclosure of such results may increase public willingness to participate in genomic research [14,40-44]. Previous studies have found that in the context of genetic testing, participants are generally more interested in receiving their individual results, but were also interested in aggregate results [45]. Focus groups conducted with prospective biobank participants reveal that the nature of the research and the type of research result affect participants' opinions about the kind of feedback $[43,46]$. A recent quantitative survey arrived at the conclusion that preference for the return of biobank research results varied depending on disease conditions (serious vs. mild) and availability of treatment [44]. At the same time, a considerable majority in this survey preferred feedback even when there is uncertainty about the result's meaning. Because of the often predictive nature of genomic information for future health and reproduction, a significant proportion of family members of participants want to be informed as well about genomic characteristics that might affect their life, e.g: having a hereditary risk for colon cancer [47-49].

While the few existing empirical data either stress that prospective participants as well as the general public value confidentiality of genomic data and the return of research results, few studies illuminate the perceptions and attitudes of patients who are already enrolled in genomic research. For instance, oncology patients are increasingly approached to participate in genomic research as genomic testing is further integrated into cancer care [50]. There is some work comparing different groups, e.g: participants having a genetic or other clinical condition, or being an affected adult or parent of an affected child $[2,18,51]$. But comparative data based on national differences are still sparse. The study presented here was conducted in three European countries (Germany, the UK, and Belgium) and surveys breast cancer patients who had provided tumor tissue samples from which genomic data were extracted for research purposes.

In this study, we explore participant attitudes regarding third-party disclosure of genomic research data and their expectations of being informed about genomic study findings and of sharing the findings with others, in particular with family members. Therefore, this study is guided by the following questions:

- What kind of study results should be protected against unauthorized disclosure?

- What kind of study findings do participants want to receive?

- How should the feedback process be organized?

- Who else should be informed about study findings?

\section{Materials and Methods}

\section{Study sample}

Data were collected by breast cancer centers in the United Kingdom, Belgium and Germany. Patients were eligible for inclusion in our survey if they had previously agreed that their blood or other tissue samples could be used for future breast cancer research (open-ended consent). In UK, the Oxford Radcliffe Hospitals NHS Trust recruited 122 participants from January 2010 to February 2011. In Belgium, 152 participants were included in the survey by the Jules Bordet Institute in Brussels from March 2009 to October 2009; in Germany, the survey was conducted from August 2009 to April 2010 in collaboration with the University Hospital in Erlangen, the Praxis Network Hematology and Internal Oncology in Troisdorf, the Breast Centre at the St. Elisabeth Hospital in Cologne and the Marien Hospital in Witten and comprised 122 participants. The local ethics committees approved the study. The response rates in Germany and Belgium were 50\% and in the UK 70\%. Recruitment and methods are described more fully elsewhere [52]. 
Citation: Petersen I, Kollek R (2015) The Symbolic Relevance of Feedback: Return and Disclosure of Genomic Research Results of Breast Cancer Patients in Belgium, Germany and the UK. J Clin Res Bioeth 6: 230. doi:10.4172/2155-9627.1000230

\section{Survey}

We surveyed the perceptions and attitudes of breast cancer patients on disclosure, confidentiality and feedback of genomic and other health-related data. The designed questionnaire is based on a review of existing empirical studies. The questions underwent a content validity assessment with the clinical partners at the Jules Bordet Institute and Oxford University. Finally, the questionnaire was piloted with 10 breast cancer patients enrolled in research studies at the Breast Centre of the University Medical Centre Hamburg-Eppendorf (Germany).

In order to investigate patient perceptions and attitudes regarding the protection of genomic data, we asked how patients perceive the legal protection of health information in their country. More specifically, we wanted to know if different medical information and conditions (genetic test results, family history of cancer, heart diseases, drug/ alcohol history, mental health history, HIV/Aids, Alzheimer's disease, allergies) need more privacy protection than others. Further, we asked the patients about their appraisal of disclosing medical conditions to other persons and institutions in the research setting and how they evaluated unauthorized disclosure and duties, e.g: to disclose genomic information to family members. Regarding the access to research findings, we queried the participant preferences about what to return to research participants and how the return should be organized.

\section{Analysis}

Responses to survey questions are presented as descriptive statistics for each nation. However, it is not our intention to test a-priori hypotheses whether and which attributes might be important for national differences. We cite national differences only when they are statistically relevant. Using SPSS 23.0, the responses were crosstabulated with participant appraisals of legal data protection, sociodemographic variables and nationality using Pearson's chi-square test (two-tailed). $\mathrm{P}$ values for these analyses were considered significant below the 0.05 level.

\section{Results}

\section{Demographics}

The study populations in all three national surveys were women affected by breast cancer. In the German survey, $98.3 \%$ of the patients were first diagnosed in 2009 and 2010, shortly before the survey started. The majority of the British participants were initially diagnosed a few months to up to three years before the start of the survey $(72.9 \%)$. The Belgian sample shows the longest time lapse between survey and first diagnosis; $82.8 \%$ of the patients were diagnosed three to eight years before the survey (2001-2006). The differences in time from diagnosis to filling out the questionnaire may not affect the manner in which the individuals responded the survey questions, but may affect the recollection of and involvement with the issue of research participation.

At the time of the survey, the mean age of the study population in all three countries was 55.1 years $(\mathrm{SD}=12.0)$ and participants had an average of 1.7 children $(\mathrm{SD}=1.9)$. There was a range of educational backgrounds. $47.7 \%$ of the British participants had only a high school education or less, Belgium (20.7\%) and Germany (14.7\%); however, the British survey included the largest group having a university degree (36.7\%) compared to Belgium (29.7\%) and Germany (25.9\%). In contrast to this, the German patients were the largest group having finished an apprenticeship (Germany: 59.5\%; Belgium: 24.8\%; UK: $15.6 \%)$.

\section{Perceptions and attitudes about disclosure and confidentiality of genomic data}

Survey participants were asked a series of questions about their perceptions and attitudes regarding confidentiality in genomic research. When asked about the state of data protection in the country they live in, only $9.1 \%$ of the respondents in the three national surveys were dissatisfied, whereas $43.9 \%$ were satisfied with the protection of health-related data. However, the majority (47\%) did not know what to answer and were unsure as to whether existing laws were sufficient to protect health information (Table 1).

In addition, survey participants were given a list of different types of health information containing information in particular related to genomic research (e.g: genetic test results, family history of cancer) as well as to clinical conditions (e.g: allergies, Alzheimer's disease, HIV/ Aids status, mental health history, drug/alcohol history).

For each, they were asked how important it is to protect this type of data. In all three countries, the data types that were chosen most often as being important to protect are potentially stigmatizing conditions such as mental health history (81.3\%), HIV/Aids status (75.5\%), drug/ alcohol history (67.7\%) (Table 2).

Furthermore, participants in all three surveys rated genetic test results as very sensitive data that need special privacy protection $(79.0 \%)$, whereas family history of cancer rated comparably lower (64.9\%). With regard to nationality, responses generally did not differ significantly, except in cases of genomic data, i.e: genetic test results, $\mathrm{p}=0.02$; family history of cancer, $\mathrm{p}=0.006$ and especially allergy data, $\mathrm{p}<0.001$. Demographic variables such as participant's age, marital status and educational level, did not have a statistically significant influence.

Queried about third-party disclosure of health information, survey participants believed that disclosure of health information without patient's consent is likely to happen, in particular disclosure to medical providers and hospital workers (63.6\%), family members (40.7\%) and public health authorities, e.g: cancer registries (40.4\%) (Table 3).

The number of British participants who believed that disclosure to third parties without patient's consent is likely was significantly less

\begin{tabular}{|c|c|c|c|c|}
\hline \multicolumn{5}{|c|}{ Do you think that existing laws adequately protect health information? } \\
\hline & $\begin{array}{c}\text { GER } \\
(\mathbf{n = 1 2 2})\end{array}$ & $\begin{array}{c}\text { UK } \\
(\mathbf{n = 1 2 2})\end{array}$ & $\begin{array}{c}\text { B } \\
(\mathbf{n}=\mathbf{1 5 2})\end{array}$ & $\begin{array}{c}\text { Total } \\
(\mathbf{n}=\mathbf{3 9 6})\end{array}$ \\
\hline Yes & $45.1 \%$ & $47.5 \%$ & $40.1 \%$ & $43.9 \%$ \\
\hline No & $10.7 \%$ & $4.1 \%$ & $11.8 \%$ & $9.1 \%$ \\
\hline Don't know & $44.3 \%$ & $48.3 \%$ & $48.0 \%$ & $47.0 \%$ \\
\hline
\end{tabular}

Table 1: Participant appraisal of data protection legislation in their country

\begin{tabular}{|l|c|c|c|c|}
\hline \multicolumn{5}{|c|}{ How important is it to protect certain types of health information? } \\
\hline Protection is important & $\begin{array}{c}\text { GER } \\
\text { (n=122) }\end{array}$ & $\begin{array}{c}\text { UK } \\
(\mathbf{n = 1 2 2})\end{array}$ & $\begin{array}{c}\text { B } \\
\text { (n=152) }\end{array}$ & $\begin{array}{c}\text { Total } \\
(\mathbf{n = 3 9 6 )}\end{array}$ \\
\hline Mental health history & $84.4 \%$ & $79.5 \%$ & $80.3 \%$ & $81.3 \%$ \\
\hline Heart diseases & $62.3 \%$ & $66.4 \%$ & $61.9 \%$ & $63.4 \%$ \\
\hline Genetic test results (p=0.02) & $82.8 \%$ & $73.0 \%$ & $80.9 \%$ & $79.0 \%$ \\
\hline Drug/alcohol history & $63.9 \%$ & $66.3 \%$ & $71.7 \%$ & $67.7 \%$ \\
\hline HIVIAids & $82.8 \%$ & $72.1 \%$ & $77.6 \%$ & $77.5 \%$ \\
\hline Family history of cancer (p=0.006) & $69.7 \%$ & $65.5 \%$ & $60.5 \%$ & $64.9 \%$ \\
\hline Alzheimer's disease & $61.5 \%$ & $67.2 \%$ & $61.9 \%$ & $63.4 \%$ \\
\hline Allergies (p<0.001) & $36.1 \%$ & $61.5 \%$ & $40.8 \%$ & $45.7 \%$ \\
\hline
\end{tabular}

Table 2: Participant appraisal of the importance to protect health information. 
Citation: Petersen I, Kollek R (2015) The Symbolic Relevance of Feedback: Return and Disclosure of Genomic Research Results of Breast Cancer Patients in Belgium, Germany and the UK. J Clin Res Bioeth 6: 230. doi:10.4172/2155-9627.1000230

\begin{tabular}{|l|c|c|c|c|}
\hline $\begin{array}{l}\text { Are the following individuals or institutions in your opinion able to access } \\
\text { health information about a person without his/her knowledge? }\end{array}$ \\
\hline Data transfer is likely & $\begin{array}{c}\text { GER } \\
\text { (n=122) }\end{array}$ & $\begin{array}{c}\text { UK } \\
\text { (n=122) }\end{array}$ & $\begin{array}{c}\text { B } \\
(\mathbf{n = 1 5 2 )}\end{array}$ & $\begin{array}{c}\text { Total } \\
(\mathbf{n = 3 9 6})\end{array}$ \\
\hline Family members & $49.2 \%$ & $23.0 \%$ & $48.0 \%$ & $40.7 \%$ \\
\hline Insurance companies & $30.3 \%$ & $22.1 \%$ & $27.0 \%$ & $26.5 \%$ \\
\hline Employers & $9.8 \%$ & $6.6 \%$ & $11.8 \%$ & $9.6 \%$ \\
\hline Hospital workers/healthcare providers & $67.2 \%$ & $46.7 \%$ & $74.3 \%$ & $63.6 \%$ \\
\hline Public health authorities & $39.3 \%$ & $36.1 \%$ & $44.7 \%$ & $40.4 \%$ \\
\hline
\end{tabular}

Table 3: Participant appraisal of the likelihood of disclosure without consent.

\begin{tabular}{|c|c|c|c|c|}
\hline \multicolumn{5}{|c|}{$\begin{array}{l}\text { Would you agree that health information be given to the following individuals } \\
\text { or institutions without the person's permission? }\end{array}$} \\
\hline Data transfer is not accepted & $\begin{array}{c}\text { GER } \\
(n=122)\end{array}$ & $\underset{(n=122)}{U K}$ & $\begin{array}{c}B \\
(n=152)\end{array}$ & $\begin{array}{c}\text { Total } \\
(n=396)\end{array}$ \\
\hline Family members & $50.8 \%$ & $50.8 \%$ & $43.4 \%$ & $48.0 \%$ \\
\hline Insurance companies & $84.4 \%$ & $72.21 \%$ & $88.8 \%$ & $82.3 \%$ \\
\hline Employers & $83.6 \%$ & $77.0 \%$ & $90.8 \%$ & $84.3 \%$ \\
\hline Healthcare providers & $37.7 \%$ & $28.7 \%$ & $19.1 \%$ & $27.8 \%$ \\
\hline Public health authorities & $34.4 \%$ & $65.6 \%$ & $87.5 \%$ & $64.4 \%$ \\
\hline
\end{tabular}

Table 4: Participant acceptance of unauthorized disclosure.

than the Belgian and German participants, i.e: family members $(23 \%$, $\mathrm{p}<0.001)$ and medical providers $(46.7 \%, \mathrm{p}<0.001)$ (Table 4$)$.

However, on average, only $27.8 \%$ in all three countries reported that they would not accept an unauthorized disclosure to medical providers compared to $60.1 \%$ of the respondents who would accept it; $2.8 \%$ stated 'I don't care', and 9.3\% did not know what to answer.

Interestingly, $48.0 \%$ of the survey participants would not want health information to be disclosed to family members without personal authorization. The vast majority stated that they did not accept data transfer to insurance companies $(82.3 \%)$ and employers (84.3\%), whereas $64.4 \%$ would not accept unauthorized disclosure to public health authorities. In the national surveys, the results showed significant differences in attitude towards public health authorities: Only $34.4 \%$ of the German respondents did not accept unauthorized data transfer to cancer registries, whereas $65.6 \%$ in the UK and even $87.5 \%$ in the Belgian sample did not want their health data transferred to public health authorities and registries.

We also asked the survey participants about their outlook on disclosing genetic or other information on hereditary diseases within a family. The majority of survey participants think that it is the responsibility of family members to share information on such conditions with other family members (Table 5).

However, most of them did not want such information to be disclosed without the permission of the affected person. Only $34.4 \%$ of the respondents agreed with the statement 'People should have access to information on a genetic condition about a person in their family without that person's permission', while $70.2 \%$ disagreed with it.

At the same time, the majority underlined a duty to disclose genetic conditions within the family. They assigned responsibility to disclose genetic conditions that might affect other family members to the patient $(70.2 \%)$ as well as to the attending physician (54.5\%).

\section{Expectations about receiving research results}

In the three national surveys, nearly all respondents (87.6\%) stated that research participants should have access to aggregate research findings resulting from the study they participated in (Table 6). The greatest interest was shown by the German respondents (92.6\%), followed by the Belgian (88.2\%) and the British respondents (82.0\%).

The survey participants were also asked about their preference with regard to the way they wish to be contacted (Table 7). About half of them stated that a circular letter by mail would be most appropriate (52.8\%); only $20.5 \%$ of respondents in the German survey, but $36.1 \%$ of the British and $32.2 \%$ of the Belgian respondents, would appreciate Internet-based information $(\mathrm{p}=0.02)$. Fewer respondents in the three countries considered a flyer available to the public (24.2\%), an information event $(11.6 \%)$ or an article in a scientific journal (14.6\%) as being suitable forms of contact.

In addition to aggregate study results, research participants thought that they should be informed about individual results that might be relevant for the development, prognosis or treatment of their cancer. Nearly $60 \%$ in the Belgian and German sample and the majority of

\begin{tabular}{|l|c|c|c|c|}
\hline Approval & $\begin{array}{c}\text { GE } \\
(\mathbf{n = 1 2 2})\end{array}$ & $\begin{array}{c}\text { UK } \\
(\mathbf{n = 1 2 2})\end{array}$ & $\begin{array}{c}\text { B } \\
(\mathbf{n = 1 5 2})\end{array}$ & $\begin{array}{c}\text { Total } \\
(\mathbf{n = 3 9 6})\end{array}$ \\
\hline $\begin{array}{l}\text { 'People should have access to } \\
\text { information on a genetic condition } \\
\text { about a person in their family without } \\
\text { that person's permission' }\end{array}$ & $32.5 \%$ & $39.2 \%$ & $32.0 \%$ & $34.4 \%$ \\
\hline $\begin{array}{l}\text { 'It is the responsibility of family } \\
\text { members to share information on } \\
\text { genetic conditions that might affect } \\
\text { other family members' }\end{array}$ & $68.0 \%$ & $77.9 \%$ & $65.8 \%$ & $70.2 \%$ \\
\hline $\begin{array}{l}\text { 'The attending doctor should contact } \\
\text { family members of his or her patient } \\
\text { who might be affected by the patient's } \\
\text { genetic condition' }\end{array}$ & $53.3 \%$ & $48.4 \%$ & $60.5 \%$ & $54.5 \%$ \\
\hline
\end{tabular}

Table 5: Participant appraisal of data confidentiality within the family.

Should a patient have access to general research findings of the study he/ she has taken part in?

\begin{tabular}{|l|c|c|c|c|}
\hline Feedback of aggregate results & $\begin{array}{c}\text { GER } \\
(\mathbf{n = 1 2 2})\end{array}$ & $\begin{array}{c}\text { UK } \\
(\mathbf{n = 1 2 2})\end{array}$ & $\begin{array}{c}\text { B } \\
(\mathbf{n}=152)\end{array}$ & $\begin{array}{c}\text { Total } \\
(\mathbf{n = 3 9 6})\end{array}$ \\
\hline Yes & $92.6 \%$ & $82.0 \%$ & $88.2 \%$ & $87.6 \%$ \\
\hline No & $6.6 \%$ & $2.5 \%$ & $6.6 \%$ & $5.3 \%$ \\
\hline Don't know & $0.8 \%$ & $15.6 \%$ & $5.3 \%$ & $7.1 \%$ \\
\hline
\end{tabular}

Table 6: Participant expectations about receiving aggregate research results.

\begin{tabular}{|l|c|c|c|c|}
\hline What kind of access do you think research participants would prefer? \\
\hline Contact & $\begin{array}{c}\text { GER } \\
(\mathbf{n = 1 2 2})\end{array}$ & $\begin{array}{c}\text { UK } \\
(\mathbf{n = 1 0 8})\end{array}$ & $\begin{array}{c}\text { B } \\
(\mathbf{n = 1 5 2 )}\end{array}$ & $\begin{array}{c}\text { Total } \\
(\mathbf{n = 3 8 2})\end{array}$ \\
\hline Circular letter by mail (p=0.03) & $56.6 \%$ & $44.4 \%$ & $60.5 \%$ & $52.8 \%$ \\
\hline Internet website (p=0.02) & $20.5 \%$ & $36.1 \%$ & $32.2 \%$ & $28.5 \%$ \\
\hline Flyer available to the public & $27.0 \%$ & $19.4 \%$ & $27.6 \%$ & $24.2 \%$ \\
\hline Article in a scientific journal & $11.5 \%$ & $15.7 \%$ & $17.8 \%$ & $14.6 \%$ \\
\hline Information event & $11.5 \%$ & $11.1 \%$ & $13.3 \%$ & $11.6 \%$ \\
\hline
\end{tabular}

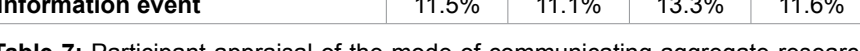
results.

Should a patient be informed about research results that might be relevant for the development, prognosis or treatment of his/her cancer?

Feedback of individual results

\begin{tabular}{|l|l|l|l|l|}
\hline Yes, under all circumstances & $58.2 \%$ & $51.6 \%$ & $58.6 \%$ & $56.3 \%$ \\
\hline
\end{tabular} \begin{tabular}{l|l|l|l|} 
GER & UK & B & Total
\end{tabular} $(n=122) \quad(n=122) \quad(n=152) \quad(n=396)$

\begin{tabular}{|l|l|l|l|l|}
\hline Yes, but only if the information is validated & $15.6 \%$ & $14.6 \%$ & $12.5 \%$ & $14.6 \%$ \\
\hline
\end{tabular}

\begin{tabular}{|l|l|l|l|l|l|}
\hline Yes, but only if treatment is available & $15.6 \%$ & $18.9 \%$ & $19.7 \%$ & $18.2 \%$ \\
\hline
\end{tabular} \begin{tabular}{|l|l|l|l|l|}
\hline $\begin{array}{l}\text { No, nobody wants to know anything that } \\
\text { he/she had not asked for }\end{array}$ & $2.5 \%$ & $0.0 \%$ & $0.7 \%$ & $1.0 \%$ \\
\hline
\end{tabular}

\begin{tabular}{|l|l|l|l|}
\hline $2.5 \%$ & $0.0 \%$ & $0.7 \%$ & $1.0 \%$ \\
\hline $0.8 \%$ & $15.6 \%$ & $5.3 \%$ & $7.1 \%$ \\
\hline
\end{tabular}

Don't know

ceiving individual research results. 


\begin{tabular}{|l|c|c|c|c|}
\hline What kind of access do you think research participants would prefer? \\
\hline Contact & $\begin{array}{c}\text { GER } \\
(\mathbf{n = 1 1 0 )}\end{array}$ & $\begin{array}{c}\text { GB } \\
(\mathbf{n = 9 6 )}\end{array}$ & $\begin{array}{c}\text { B } \\
(\mathbf{n = 1 3 7 )}\end{array}$ & $\begin{array}{c}\text { Total } \\
(\mathbf{n = 3 4 3 )}\end{array}$ \\
\hline Circular letter by mail (p=0.003) & $14.5 \%$ & $34.4 \%$ & $28.5 \%$ & $25.7 \%$ \\
\hline Consultation with the doctor & $85.5 \%$ & $65.6 \%$ & $71.5 \%$ & $74.3 \%$ \\
\hline
\end{tabular}

Table 9: Participant appraisal of the mode of communicating individual research results.

the British respondents supported an unconditional duty to return individual results to the study participant (together: $56.3 \%$; Table 8).

$18.2 \%$ in the three national surveys approved the statement that only validate results found for an individual during the course of research had to be returned to the person concerned and $14.6 \%$ believed that the feedback should only be mandatory if treatment is available. Asked about the preferred mode of communication, about two thirds of the survey respondents thought that consultation by the attending doctor is the most suitable ( $74.3 \%$ ); only $25.7 \%$ preferred a letter by mail (Table 9 ).

Only the British survey differed significantly. Compared to the other surveys, more respondents approved the contact in writing, i.e: UK (34.4\%), Germany (14.5\%) and Belgium (28.5\%) ( $\mathrm{p}=0.003)$.

\section{Discussion}

Current bioethical debates on privacy and confidentiality in genomic research have not sufficiently dealt with the subject of an ethical duty to return individual study results, and empirical studies exploring the attitude of patients who have experienced research participation towards this duty are sparse. However, empirical evidence on the participant's privacy concerns and their expectations about receiving aggregate and individual study results may reveal new insights on the conceptualization of this duty. Patient or participant perceptions on what matters to them and how they want the tension between privacy and access to be solved may provide a way out of the dilemma that serves both goals.

Empirical studies on prospective and current biobank participants have on the one hand documented profound concerns of privacy breaches and genetic discrimination $[14,15,17,46]$, and on the other hand, research participants express a high desire for receiving findings from genomic studies [40-43]. Empirical studies on both issues have, however, recently moved on to investigate the meaning and value of confidentiality and feedback by looking at the context in which it is applied and used. There is, for example, empirical evidence that data confidentiality can be displaced by other values such as data control or trust in research institutions [13,17,21]. Depending on disease conditions or availability of disease treatment, preferences for feedback can vary as well [44].

Being aware of this blank space in research, our survey pursued three goals. First, we aimed at jointly studying attitudes and perceptions of confidentiality and unauthorized disclosure of genomic research data, and then looked at expectations of receiving feedback on study findings and of sharing them with others, in particular with family members. Thereby, we were seeking the meanings and values ascribed by the participants towards data confidentiality and return of research results in the other's context. Second, we aimed to survey participants who were directly affected by genomic research. Third, we aimed to compare their attitudes and perceptions in different national contexts, namely Germany, the UK, and Belgium.

Summing up our survey results, data have shown that only half of the respondents believe that legislation in their country is sufficient to protect health information. $47 \%$ of the respondents were not able to answer the question as to whether existing laws do a good job of protecting health information. In order to find out what data people want to be protected the most, we asked how severe they would rate privacy violations regarding different health conditions. It became clear that privacy concerns depend on the potential of the condition for social stigmatization, since mental health history and the HIV/Aids status were cited most as important to be protected. Privacy protection of drug/alcohol history was also rated high, but is not perceived to be as stigmatizing as mental health history. Genomic data or genetic test results were evaluated as very sensitive data, whereas a family history of cancer as a concrete hereditary condition scored comparably lower As a reason for this, it can be assumed that at least some respondents were not aware of the direct link between a genomic background and a family history of disease.

Queried about third-party disclosure, $48 \%$ of the three national surveys stressed that they would not want that health information to be disclosed to family members without personal authorization. This attitude correlates with the refusal of the right to know about a hereditary disease among family members by more than $50 \%$ of the surveyed individuals. However, at the same time, $70 \%$ of the respondents ascribed responsibility to the diagnosed individual to disclose a genetic condition to the family. Asking for the role of the physician in family disclosure, about half of the respondents approved of he or she contacting family members who might have inherited the genetic condition as well. However, $40 \%$ of the respondents believed that disclosure to family members without consent is likely anyway. They also assumed that medical providers, hospital workers and public health authorities and registries are able to access health information through disclosure without consent. However, two thirds of the respondents would accept disclosure without consent to medical providers, but considerably fewer would agree with reporting health information to public health authorities without authorization. In particular the Belgian respondents seem to worry that health registries disclose patient data to third parties. Confirming previous studies, more than $80 \%$ wanted to be protected against non-authorized data transfer to insurance companies and employers.

Our survey supports previous findings of other studies that participants in genomic research want to receive feedback of research results. We found the desire to receive general study findings such as a summary of aggregate results drawn from the study population to be very high. Asked about the preferred mode of contact, the majority voted for a circular letter by mail. Surprisingly, the national surveys significantly differed with regard to preference for Internet-based information: Even though Internet usage of the total population in Germany, the UK and Belgium is about $80 \%$, only one fifth of the queried Germans but about one third in the British and Belgian respondents appreciated information from Internet-based sources. Only half of the study population supported an unconditional duty to return individual research results to the study participant. A considerable portion of participants wanted to be informed only under certain conditions, in particular validation and clinical utility. However, taking the approvals (unconditional and under certain conditions) together, about $90 \%$ of the respondents called for a duty to provide feedback of individual study results. Asked about the preferred mode of communication, about three fifths of the survey respondents thought that the attending doctor should give feedback about individual study results.

There are some limitations to this study. The choice of survey participants was based on personal collaborations within the EU 
research project "Advancing Clinico Genomic Trials on Cancer" (FP6-IST-026996) und did not follow decisive predetermined criteria. However, although part of the European Union, Germany, the UK, and Belgium represent three countries with different languages, sociocultural and economic backgrounds and slightly different health care systems. The differences make the chosen countries in general suitable for such a comparative study. Furthermore, as far as we know, no nationally comparative data about participant perspectives on disclosure, confidentiality and the return of genomic data on breast cancer are available. Due to the international research setting, we were also not able to keep the survey participant's clinical and demographic parameters uniform (e.g: type of clinical trials the participants were involved in, the time between survey and first diagnosis, age and educational level)

\section{Conclusion}

The sampled population in our survey was breast cancer patients who provided blood or other tissue samples to genomic cancer research. Despite their consent to participate in research, they had considerable concerns regarding personal risks of disadvantage from privacy violations in the context of the research setting and were fairly unconfident whether existing data protection measures adequately safeguard them. Previous studies with prospective volunteers have even shown that privacy concerns impede the willingness to participate in research [12,13]. Hence, it is crucial to understand under which conditions people are eventually willing to risk privacy and provide biomaterial for research purposes. From an anthropological perspective, it has been argued that people maintain a complex relationship with donated tissue, because they regard it as something both personal and something private [53]. That is why they tend to attach terms of requirements to their research contribution and expect some form of reciprocity from researchers or research institutions. However, they rarely want money in return; usually they expect care and appreciation. This confirms that reciprocity can be handled in multiple ways as each relationship enacts its own set of expectations [54]. By characterizing the general tension between data privacy and access to research results, we asked whether some forms of reciprocity may provide a way out of the dilemma that serves the participant's desire for both privacy and access to study findings.

Our survey suggests that participant expectations regarding what to receive in return for their research participation and tissue donation can be quite symbolic. The return does not necessarily have to be beneficial in terms of money or patient care, but needs to represent some sort of appreciation of the study participant's contribution. In all three national surveys, respondents were more satisfied to receive aggregate than individual research results. One important reason might be that relevance and meaning of detailed results from genomic research are difficult to understand and to assess and tend to create unease or insecurity. Therefore, in genomic research, aggregate results may serve the expectation to be appreciated better than the return of detailed research findings; this does not, however, dispense with the need to return specific individual findings.

Despite the fact that one of the Eurobarometer surveys suggests that perceptions and attitudes about confidentiality and privacy of health-related data are quite heterogeneous across Europe [12], our results are quite homogeneous regarding national differences. Only the British survey shows a few statistically relevant variations. However, the purpose of this paper was not to seek reasons for national differences, but was rather to explore general trends in perceptions and attitudes about return and disclosure of genomic data on breast cancer in three European countries.

\section{Acknowledgement}

We would like to thank Dr. Christine Desmedt (Jules Bordet Institute), Dr Francesca Buffa and Dr. Adrian Harris (The Weatherall Institute of Molecula Medicine, University of Oxford) for participating in the design of the study and collecting the data, Christin Tschammler and Dr. Christian Bayer (University Hospital in Erlangen), Bettina Buergel (Praxis Network Haematology and Interna Oncology in Troisdorf), Sigrun Wolfsturm (Breast Centre at the St. Elisabeth Hospital in Cologne), Katja Fritz (Marien Hospital in Witten), Michaela Luz (West German Study Group in Moenchengladbach) for their excellent support in collecting the data as well as the hospitals and especially the patients participating in the survey. Our research received funding from the EU through the research project “Advancing Clinico Genomic Trials on Cancer (ACGT)” (FP6-IST-026996).

\section{References}

1. Raikka J (2007) Autonomy and genetic privacy: Genetic Democracy. Philosophical Perspectives. Dordrecht Springer 37: 43-51.

2. Johnson S, Kass NE, Natowicz M(2005) Disclosure of personal medical information: differences among parents and affected adults for genetic and nongenetic conditions. Genet Test 9: 269-280.

3. Lowrance WW, Collins FS (2007) Ethics. Identifiability in genomic research Science 317: 600-602

4. Tavani HT (2004) Genomic research and data-mining technology implications for personal privacy and informed consent. Ethics Inf Technol 6: 15-28.

5. Heeney C, Hawkins N, de Vries J, Boddington P, Kaye J (2011) Assessing the privacy risks of data sharing in genomics. Public Health Genomics 14: 17-25.

6. Knoppers BM, Abdul-Rahman MH (2009) Health privacy in genetic research Politics Life Sci 28: 99-101.

7. Gottweis $\mathrm{H}$, Chen $\mathrm{H}$, Starkbaum J (2011) Biobanks and the phantom public Hum Genet 130: 433-440.

8. Bialobrzeski A, Ried J, Dabrock P (2011) Privacy revisited? Old ideals, new realities, and their impact on biobank regimes. Poiesis Prax 8: 9-24

9. Svantesson DJB (2013) Extraterritoriality in Data privacy law. Copenhagen: Ex Tuto Publishing 3: 278-286.

10. Reichel J, Lind AS (2015) The new General Data Protection Regulation-Where are we are and where might we be heading? In: Ethics, law and governance of biobanking. Dordrecht: Springer 14: 95-100.

11. Social TO (2010)Attitudes on data protection and electronic identity in the European Union. A report to the European Commission Special Eurobarometer 359.

12. Gaskell G, Stares S, Allansdottir A, Allum N, Castro P (2010) Europeans and biotechnology in 2010. Winds of change? Report to the European Commission.

13. Gaskell G, Gottweis H, Starkbaum J, Gerber MM, Broerse J et al. (2013) Publics and biobanks: Pan-European diversity and the challenge of responsible innovation. European Journal of Human Genetics 21: 14-20.

14. Kaufman DJ, Bollinger MJ, Scott J, Hudson KL (2009) Public opinion about the importance of privacy in biobank research. Am J Hum Genet 85: 643-654.

15. Lemke AA, Wolf WA, Beirne HJ, Smith ME (2010) Public and biobank participant attitudes toward genetic research participation and data sharing. Public Health Genomics 13: 368-377.

16. Hobbs A, Starkbaum J, Gottweis U, Wichmann HE, Gottweis H (2012) The privacy-reciprocity connection in biobanking: comparing German with UK strategies. Public Health Genomics 15: 272-284.

17. Jamal L, Sapp JC, Lewis K, Yanes T, Facio FM, et al. (2014) Research participants' attitudes towards the confidentiality of genomic sequence information. Eur J Hum Genet 22: 964-968.

18. Kass NE, Hull SC, Natowicz MR, Faden RR, Plantinga L, et al. (2004) Medical privacy and the disclosure of personal medical information: the beliefs and experiences of those with genetic and other clinical conditions. Am J Med Genet A 128: 261-270.

19. Billings PR, Kohn MA, de Cuevas M, Beckwith J, Alper JS, et al. (1992) Discrimination as a consequence of genetic testing. Am J Hum Genet. 50: 476 482. 
Citation: Petersen I, Kollek R (2015) The Symbolic Relevance of Feedback: Return and Disclosure of Genomic Research Results of Breast Cancer Patients in Belgium, Germany and the UK. J Clin Res Bioeth 6: 230. doi:10.4172/2155-9627.1000230

20. Geller LN, Alper JS, Billings PR, Barash Cl, Beckwith J, et al. (1996) Individual, family, and societal dimensions of genetic discrimination: a case study analysis. Sci Eng Ethics 2: 71-88.

21. Snell K, Starkbaum J, Laub G, Vermeer A, Helen I (2012) From protection of privacy to control of data streams: a focus group study on biobanks in the information society. Public Health Genomics 15: 293-302.

22. Solove D (2007) 'I've got nothing to hide' and other misunderstandings of privacy. San Diego Law Review 44 p. 745.

23. Im HK, Gamazon ER, Nicolae DL, Cox NJ (2012) On sharing quantitative trait GWAS results in an era of multiple-omics data and the limits of genomic privacy. Am J Hum Genet 90: 591-598.

24. Jacobs KB, Yeager M, Wacholder S, Craig D, Kraft P, et al. (2009) A new statistic and its power to infer membership in a genome-wide association study using genotype frequencies. Nat Genet 41: 1253-1257.

25. Stephenson J (1996) Pathologists enter debate on consent for genetic research on stored tissue. JAMA 275: 503-504.

26. Bredenoord AL, Kroes HY, Cuppen E, Parker M, van Delden JJ (2011) Disclosure of individual genetic data to research participants: the debate reconsidered. Trends Genet 27: 41-47.

27. Johnson G, Lawrenz F, Thao M (2012) An empirical examination of the management of return of individual research results and incidental findings in genomic biobanks. Genet Med 14: 444-450.

28. Bredenoord AL, Moret ONC, Van Delden JJ (2011) Feedback of individual genetic results to research participants: in favor of a qualified disclosure policy. Hum Mutat 32: 861-867.

29. Beskow LM, Burke W, Merz JF, Barr PA, Terry S, et al. (2001) Informed consent for population-based research involving genetics. Jama 286: 2315-2321.

30. Fernandez CV, Kodish E, Weijer C (2003) Informing study participants of research results: an ethical imperative. Irb 25: 12-19.

31. Partridge AH, Winer EP (2002) Informing clinical trial participants about study results. Jama 288: 363-365

32. Bookman EB, Langehorne AA, Eckfeldt JH, Glass KC, Jarvik GP, et al. (2006) Reporting genetic results in research studies: summary and recommendations of an NHLBI working group. Am J Med Genet A 140: 1033-1040.

33. Knoppers BM, Joly Y, Simard J, Durocher F (2006) The emergence of an ethical duty to disclose genetic research results: international perspectives. Eur J Hum Genet 14: 1170-1178.

34. Ravitsky V, Wilfond BS (2006) Disclosing individual genetic results to research participants. Am J Bioeth 6: 8-17.

35. Renegar G, Webster CJ, Stuerzebecher S, Harty L, Ide SE, et al. (2006) Returning genetic research results to individuals: points-to-consider. Bioethics 20: 24-36.

36. Murphy J, Scott J, Kaufman D, Geller G, LeRoy L, et al. (2008) Public expectations for return of results from large-cohort genetic research. Am J Bioeth 8: 36-43.

37. Kollek R, Petersen I (2011) Disclosure of individual research results in clinicogenomic trials: challenges, classification and criteria for decision-making. J Med Ethics 37: 271-275.

38. Lolkema MP, Gadellaa-van Hooijdonk CG, Bredenoord AL, Kapitein P, Roach $\mathrm{N}$, et al. (2013) Ethical, legal, and counseling challenges surrounding the return of genetic results in oncology. J Clin Oncol 31: 1842-1848.

39. Ormond KE, Wheeler MT, Hudgins L, Klein TE, Butte AJ, et al. (2010) Challenges in the clinical application of whole-genome sequencing. Lancet 375: $1749-1751$
40. Shalowitz DI, Miller FG (2008) Communicating the results of clinical research to participants: attitudes, practices, and future directions. PLoS Med 5: e91.

41. Cadigan RJ, Michie M, Henderson G, Davis AM, Beskow LM (2011) The meaning of genetic research results: reflections from individuals with and without a known genetic disorder. J Empir Res Hum Res Ethics 6: 30-40.

42. Meulenkamp TM, Gevers SK, Bovenberg JA, Koppelman GH, van Hylckama Vlieg A, et al. (2010) Communication of biobanks' research results: what do (potential) participants want? Am J Med Genet A 152A: 2482-2492.

43. Beskow LM, Smolek SJ (2009) Prospective biorepository participants' perspectives on access to research results. J Empir Res Hum Res Ethics 4 99-111.

44. Allen NL, Karlson EW, Malspeis S, Lu B, Seidman CE, et al. (2014) Biobank participants' preferences for disclosure of genetic research results: perspectives from the OurGenes, OurHealth, OurCommunity project. Mayo Clin Proc 89: 738-746.

45. Kaphingst KA, Janoff JM, Harris LN, Emmons KM (2006) Views of female breast cancer patients who donated biologic samples regarding storage and use of samples for genetic research. Clinical Genetics 69: 393-398.

46. Bollinger JM, Scott J, Dvoskin R, Kaufman D (2012) Public preferences regarding the return of individual genetic research results: findings from a qualitative focus group study. Genet Med 14: 451-457.

47. Ceballos RM, Newcomb PA, Beasley JM, Peterson S, Templeton A, et al. (2008) Colorectal cancer cases and relatives of cases indicate similar willingness to receive and disclose genetic information. Genet Test 12: 415-420.

48. Petersen GM, Larkin E, Codori AM, Wang CY, Booker SV, et al. (1999) Attitudes toward colon cancer gene testing: survey of relatives of colon cancer patients. Cancer Epidemiol Biomarkers Prev 8: 337-344.

49. Esplen MJ, Madlensky L, Aronson M, Rothenmund H, Gallinger S, et al. (2007) Colorectal cancer survivors undergoing genetic testing for hereditary nonpolyposis colorectal cancer: motivational factors and psychosocial functioning. Clin Genet 72: 394-401.

50. McGowan ML, Settersten RA, Juengst ET, Fishman JR (2014) Integrating genomics into clinical oncology: ethical and social challenges from proponents of personalized medicine. Urol Oncol 32: 187-192.

51. Plantinga L, Natowicz MR, Kass NE, Hull SC, Gostin LO,et al. (2003) Disclosure, confidentiality, and families: experiences and attitudes of those with genetic versus nongenetic medical conditions. Am J Med Genet C Semin Med Genet 119C: 51-59.

52. Petersen I, Desmedt C, Harris A, Buffa F, Kollek R (2014)Informed consent, biobank research, and locality: perceptions of breast cancer patients in three European countries. J Empir Res Hum Res Ethics 9: 48-55

53. Lauss G, Schroder C, Dabrock P, Eder J, Hamacher K, et al. (2013) Towards biobank privacy regimes in responsible innovation societies: ESBB conference in Granada 2012. Biopreserv Biobank 11: 319-323.

54. Hoeyer K (2010) Donors perceptions of consent to and feedback from biobank research: time to acknowledge diversity? Public Health Genomics 13: 345-352. 